\title{
NAO influence on extreme winter temperatures in Madrid (Spain)
}

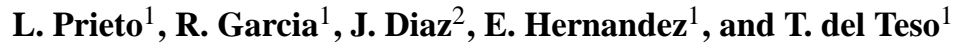 \\ ${ }^{1}$ Depto. Fisica de la Tierra II, Fac. CC. Fisicas, Univ. Complutense de Madrid, Spain \\ ${ }^{2}$ Centro Universitario de Salud Publica, Universidad Autonoma de Madrid, Spain
}

Received: 12 December 2001 - Revised: 11 June 2002 - Accepted: 17 June 2002

\begin{abstract}
Extremely cold days (ECDs), with minimum temperatures lower than $-4.6^{\circ} \mathrm{C}$, have been analysed for Madrid. This threshold corresponds to the 5th percentile of the period 1963-1999. Adopting a case analysis approach, five synoptic patterns have been identified that produce these extremely low temperatures. Three of them are associated with cold air flows over the Iberian Peninsula, and the other two with a lack of significant circulation over the region. A nonlinear association with the North Atlantic Oscillation (NAO) has been identified using log-linear models. The NAO positive phase leads to an increase in the winter frequency of those synoptic patterns associated with stagnant air flow over Iberia, while those characterised by cold, northern flows do not appear to be similarly influenced.
\end{abstract}

Key words. Meteorology and atmospheric dynamics (climatology; synoptic-scale meteorology; general or miscellaneous)

\section{Introduction}

There is a growing interest in the study of the climatic variability and of the wider consequences of extreme temperatures. Unusually low minimum temperatures have an immediate and significant influence on transport, agriculture, energy or water supply (NOAA, 1982, 1983) and, in particular, on human health. Very low temperatures are, for example, associated with influenza, pneumonia and other disorders leading to an increase in mortality. However, the impacts of minimum temperatures are not as clearly understood as those of summer extreme maxima and the existence of a temperature threshold is less evident in respect of minima (Kalkstein and Davis, 1989; Kunst et al., 1993). The association between mortality and extreme temperatures occasionally exhibits a U-shape, with a "comfort" temperature associated with a minimum of mortality, but with increasing death rates for very high or low values (Alberdi et al., 1998). The

Correspondence to: L. Prieto (luis@ 6000aire.fis.ucm.es) extreme effect cannot therefore be thought of as necessarily linear (Jendritzky, 1996; Diaz et al., 2001). On the other hand, in regions with mild climates, a degree of linearity has been found to exist between mortality and wintertime temperature (Keatinge et al., 1989; Frost and Auliciems, 1993).

During the XXth century, an increase of about $0.6^{\circ} \mathrm{C}$ has been detected in the global temperature record (Nicholls et al., 1996). This has been associated with increases in the daily minima, while maximum values have revealed a more conservative character with the result that the daily temperature range has been reduced (Karl et al., 1991, 1993). This pattern is not, however, consistent between the regions and is most marked in North America, Europe and Australia where there has also been a general decrease in the number of freezing days (Easterling et al., 2000).

These recent trends are confirmed by the results produced when running different climate models simulating the effect of increasing greenhouse gas emissions (Kattenberg et al., 1996). The results show an increase in surface temperature with significant consequences for the extremes. These vary according to the region, but suggest a trend to more (less) frequent summer (winter) extremes, and an overall decrease in the daily range (Zwiers and Kharin, 1998).

This paper describes two aspects of the behaviour of winter extreme minimum temperature in Madrid (Spain). Firstly, a statistical description is provided, followed by a review of those synoptic patterns that commonly result in very low temperatures. Finally the paper considers the association between the North Atlantic Oscillation and extreme temperature events.

\section{Extremely cold days}

When studying unusual temperatures it is important to define a threshold value beyond which the event can be classified as "extreme". There is no common agreement in the literature for such a definition, which varies depending on the research theme, which can range between health impact 
Table 1. Mean minimum temperature and, for ECDs, the month with the maximum number of events, the total frequency and the relative frequency expressed over the five SLP patterns

\begin{tabular}{lccccc}
\hline & PM & CPN & CPE & STA & BP \\
\hline Mean min. T $\left({ }^{\circ} \mathrm{C}\right)$ & -5.4 & -5.7 & -5.8 & -5.6 & -6.2 \\
Preferably month & Dec/Jan & Jan & Jan/Dec & Jan/Dec & Jan \\
Total freq. & 42 & 45 & 35 & 95 & 49 \\
Relative freq. () & 14.7 & 15.7 & 12.3 & 33.3 & 17.2 \\
\hline
\end{tabular}

(Katsouyanni et al., 1993) and trend analysis (Easterling et al., 2000). In this paper the conventional statistical criterion, of the 5th percentile value of the daily minimum temperature has been adopted as the limit for purposes of identifying those individual days with 'extreme' temperatures.

The city of Madrid, with more than 3.5 million inhabitants spread across an extensive built-up area, produces a clearly defined heat island effect that varies seasonally and with the meteorological situation. To eliminate this urban heating effect from the source data, the daily temperature series from the observatory at the airport of Madrid-Barajas has been used. This airport is located $3 \mathrm{~km}$ east of Madrid's limits and is not subject to the heat island effect (Yague et al., 1991). The series is continuous and covers the period 1962 to 1999. Data have been provided by the Spanish National Institute of Meteorology (INM).

For this series, the 5th percentile threshold corresponds to a value of $-4.6^{\circ} \mathrm{C}$ and a total of 285 days were found with a daily minimum temperature lower than this critical value. These constituted the series of Extremely Cold Days (ECD). Figure 1 shows the sequence of annual ECD frequencies for the study period to have no readily identifiable trends or patterns. The greatest number ECDs in any one year was 23 (in 1968), while 1966, 1988, 1996 and 1998 passed without any such events. Figure 2 shows the monthly ECD distribution in which it can be seen that $94 \%$ of all events occurred in the period December to February inclusive. Only 9 events were recorded during November and March. As a result of this seasonal concentration of events this paper considers the number of winter, rather than annual, ECDs. The number of occurrences assigned to the $\mathrm{n}$-th year will, consequently, correspond to the period November-March ending March of the $\mathrm{n}$-th year.

A more detailed analysis of the data suggests that the winter frequency series possesses a negative linear trend of $-0.16 \mathrm{ECD} / \mathrm{year}$. This is not, however, significant at the $95 \%$ level. Neither can any significant trend be detected in the series for winter average minima. Since the occurrence of an ECD on a given day is, by the definition adopted in this paper, a process having a probability of $<0.05$, it can be more properly described by a Poisson process. In this case, three requirements have to be satisfied:

1. The expected frequency of the event's occurrence is a constant value, $\lambda$, which is the average number of events per unit time.

2. The probability of occurrence of an event within the interval $(t, t+\Delta t)$ is, at first approximation, equal to $\lambda \Delta t$.

3. If $\Delta t$ is small enough, the probability of occurrence of more than one event in $\Delta t$ tends to zero faster than $\Delta t$.

From its definition, an ECD event clearly satisfies requirements 1 and 2. Some questions could however be raised regarding 3, since an ECD could occur under the influence of persistent cold waves (episodes with a consecutive number of days satisfying ECD conditions). However, a careful analysis of the series shows that most ECDs were isolated events and, even during cold waves, consecutive events were rare. This renders negligible the probability of consecutive ECD events, and 3 condition becomes acceptable.

The gamma distribution can help to determine the value of the Poisson parameter when a limited time series is available (Elsner and Bossak, 2001; Epstein, 1985).

Figure 3 shows the $\lambda$ distribution obtained for the number of ECDs per winter series of the whole period, it can be noted that the probability becomes non-zero only for the range $6.5-9.5$, with a maximum value at 7.8 . It follows that the expected value of the annual occurrence should be within this range if the requirements of a Poisson process were perfectly satisfied.

Given a Poisson process, characterised by a known $\lambda$ parameter, the probability to have $r$ expected events within the time interval $t$, noted as $f_{P o}(r, t)$ can be described by the Poisson distribution:

$f_{P o}(r, t)=\frac{(\lambda t)^{r}}{r !} e^{-\lambda t}$

Figure 4 shows the probability distribution of the winter number of ECDs, adjusted according to the procedure of Elsner and Bossak (2001). It must be added that the extreme recorded values (23 and 0 event per year) appear with negligible probabilities, suggesting that the process generating ECDs does not match perfectly this type of distribution. This will be discussed later in more depth.

As pointed out previously, there is no general agreement on the definition of a minimum threshold value and it could be argued that the characteristics of any ECD series are highly dependent on the chosen limit. To check this, the winter number of ECDs have been computed for thresholds between $-5.6^{\circ} \mathrm{C}$ and $-3.6^{\circ} \mathrm{C}$ with a $0.2^{\circ} \mathrm{C}$ interval (corresponding to 9 th and $3 \mathrm{rd}$ percentiles, respectively). These have been correlated against the principal series $\left(-4.6^{\circ} \mathrm{C}\right)$ and the resulting Pearson correlation coefficients are shown in Table 1 in which it can be seen that all are significant at the 99\% level. Thus, the main difference between the series lies in the absolute values of the frequencies. The series patterns are, however, very similar as can be seen in Fig. 5 where the sequences corresponding to the winter number of ECDs for $-3.6^{\circ} \mathrm{C},-4.6^{\circ} \mathrm{C}$ and $-5.6^{\circ} \mathrm{C}$ are presented. A common pattern is clearly shown, supporting the conclusion that the results are consistent over a range of threshold values. 


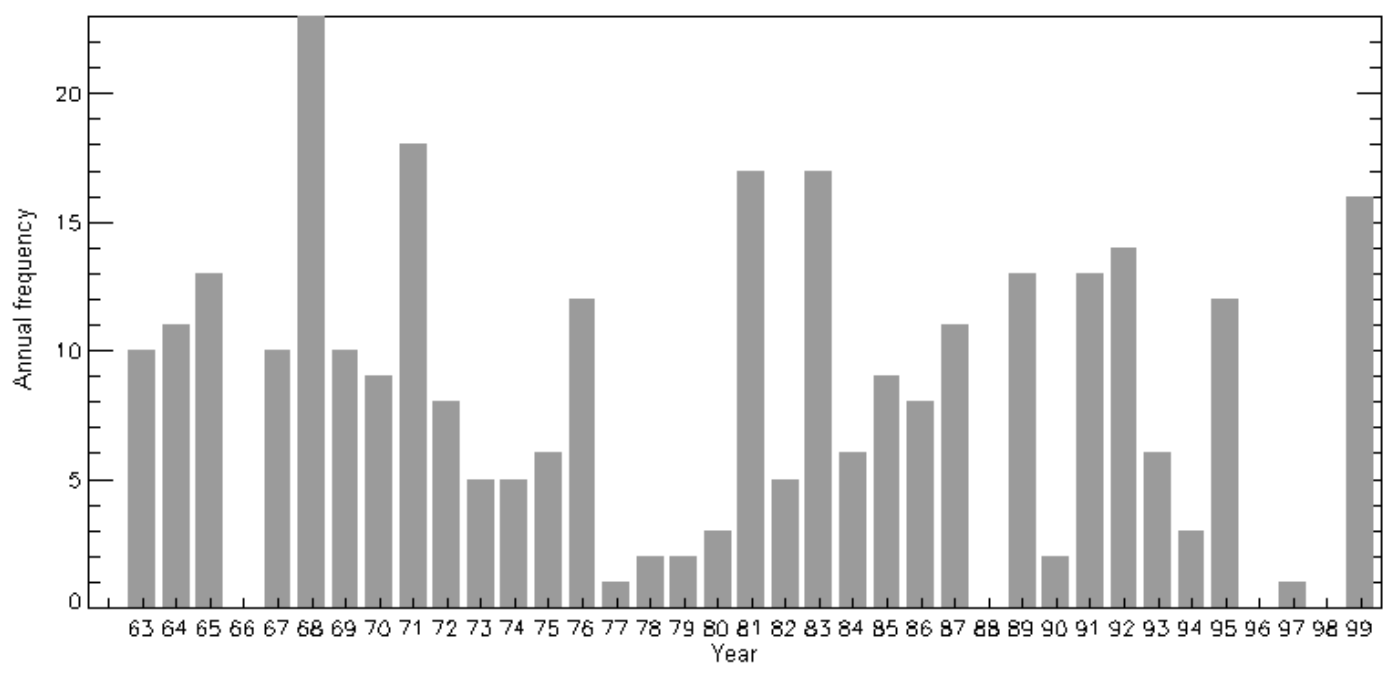

Fig. 1. Number of ECDs per winter season in Madrid during the period 1963-1999, ECD being defined the day with minimum temperature below $-4.6^{\circ} \mathrm{C}$.

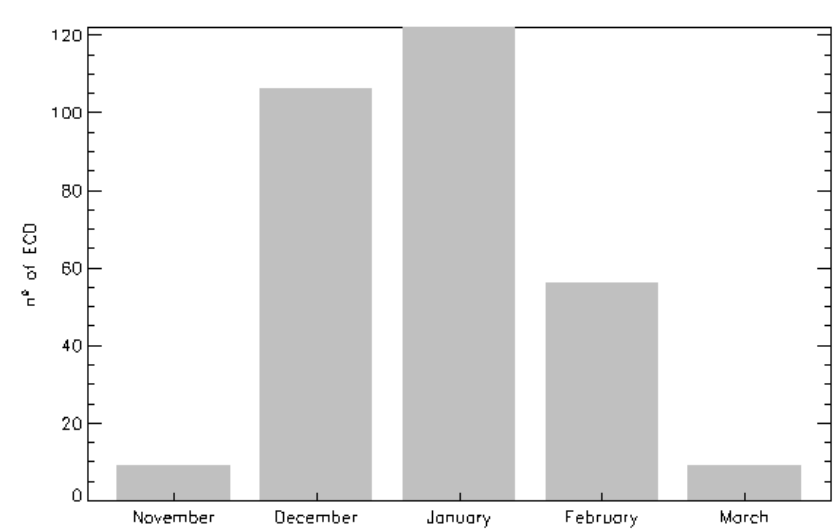

Fig. 2. Number of ECDs in function of month.

\section{Synoptic analysis of ECD}

The synoptic situations leading to the occurrence of ECD have also been analysed and classified to identify the meteorological and climatological factors that determine their behaviour. The classification has been made through a case analysis procedure based on those days with daily minimum temperature lower than $-4.6^{\circ} \mathrm{C}$. The following data from the NCEP/NCAR reanalysis (Kalnay et al., 1996) are based on 00:00 UTC data with a $2.5^{\circ} \times 2.5^{\circ}$ grid resolution. The variables include surface level pressure, geopotential height at $500 \mathrm{hPa}$ and the analysed wind at different pressure levels.

The classification procedure identified five synoptic patterns responsible for the occurrence of an ECD. Reflecting their origins, the five patterns are named as follows: Polar Maritime (PM), Continental Polar North (CPN), Continental Polar East (CPE), Stagnation (STA) and Barometric Plateau (BP). Two groups can be distinguished among these patterns: those associated with an active flow of cold air over

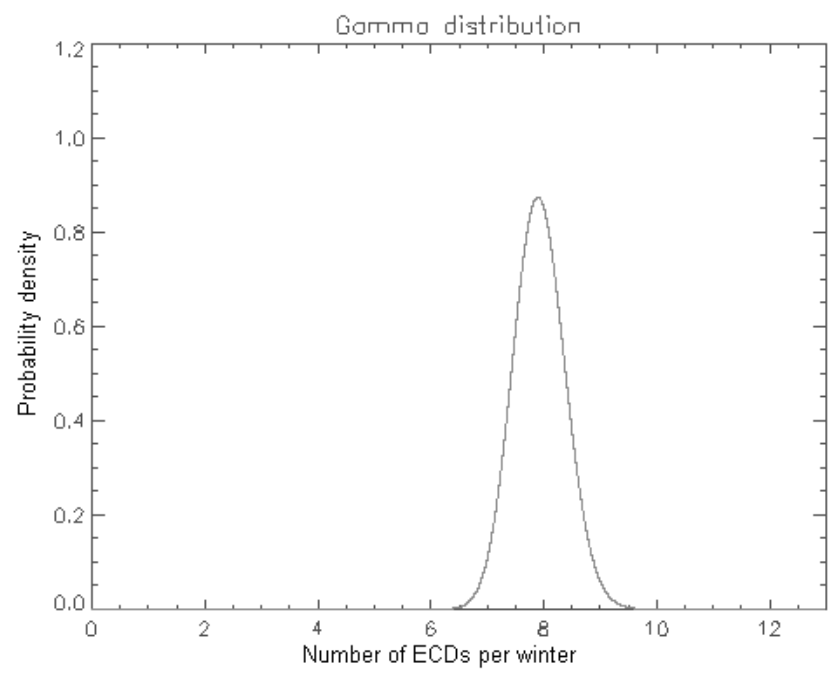

Fig. 3. Gamma distribution showing the probability density for the number of ECDs per year.

the Iberian Peninsula (PM, CPN and CPE) and those resulting from the absence of any significant circulation over the region (STA and BP). Figure 6 shows the SLP and $500 \mathrm{hPa}$ composite fields for the five patterns, whose descriptions are included below.

1. Polar Maritime (PM). This pattern is characterised by a well developed flow from the North Atlantic Ocean. It results from the presence of intense surface high pressure with a centre located northwest of the Iberian Peninsula between $40^{\circ}$ and $45^{\circ} \mathrm{N}$ and $20^{\circ} \mathrm{W}$. This surface flow is reinforced at $500 \mathrm{hPa}$ by a ridge situated in the same area (see Figs. 6a and b). The temperatures reached under this pattern are higher than those resulting from the other four synoptic types. This is because the air mass, although very cold at its source region, 
Table 2. Correlation coefficients between annual frequency series and different temperature thresholds and the chosen threshold of $-4.6^{\circ} \mathrm{C}$

\begin{tabular}{lcccccccccc}
\hline Threshold $\left({ }^{\circ} \mathrm{C}\right)$ & -5.6 & -5.4 & -5.2 & -5.0 & -4.8 & -4.4 & -4.2 & -4.0 & -3.8 & -3.6 \\
\hline Correlation coef. & 0.92 & 0.94 & 0.95 & 0.97 & 0.98 & 0.97 & 0.97 & 0.94 & 0.92 & 0.91 \\
Total frequency & 143 & 171 & 195 & 232 & 271 & 339 & 377 & 449 & 504 & 555 \\
\hline
\end{tabular}

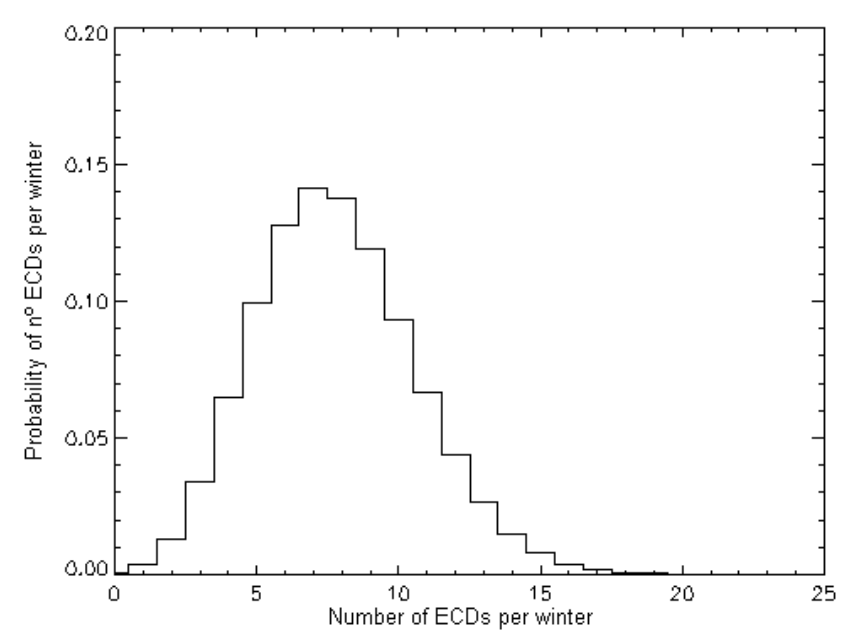

Fig. 4. Distribution of probabilities associated to the gamma distribution shown in Fig. 3.

has a trajectory that ensures a lengthy oceanic passage thereby increasing its surface temperature.

2. Continental Polar North (CPN). The composite fields associated with this pattern are similar to those of PM, but with a north-eastern displacement of the anticyclonic centre. At $500 \mathrm{hPa}$, the ridge is also displaced eastward and is now oriented northeast to southwest. Since the trajectory of this air has a much more continental character, the temperatures are lower than those associated with the PM situation. The composites for this pattern are shown in Figs. $6 \mathrm{c}$ and $\mathrm{d}$.

3. Continental Polar East (CPE). The main feature of this pattern is the intrusion of cold continental air from central Europe into Spain. Figure 6e shows how a small low pressure centre over Italy and a high pressure system over Northern Central Europe can give rise to such a flow. However, they do not need to appear simultaneously. At $500 \mathrm{hPa}$, the principal characteristic is a low centred over Italy, as can be seen in Fig. 6f. This pattern shows the lowest frequency of occurrence but produces the coldest temperatures over Madrid.

4. Stagnation (STA). Figures $6 \mathrm{~g}$ and h show how an intense anticyclone and ridge can occur simultaneously over Iberia to produce a very stable situation, with an absence of wind and clouds. This leads to strong nocturnal radiative cooling that is characteristic of this pattern, which is the most frequently occurring of the five.
5. Barometric Plateau (BP). These days are also characterised by the absence of any significant pressure gradient. However, these situations have a large core area, even greater than that for STA types, within which there is no clearly discernible pressure gradient (Fig. 6i). Although the Iberian Peninsula is again under the influence of an extensive anticyclonic area with low or nonexistent pressure gradients at $500 \mathrm{hPa}$ (Fig. 6j) a weak north-westerly flow can be detected.

Table 2 summarises some of the main characteristics of these patterns. It can be seen that the BP type produces the lowest temperatures, while the highest are associated with the PM type. As might be anticipated, December and January are the months when all the patterns occur most frequently. The STA is the most common, while CPE, although having a lower frequency is significant because it accounts for $93 \%$ of the total recorded ECDs.

\section{Influence of the North Atlantic oscillation on the ECD occurrence}

The previous paragraph has shown that the incidence of an ECD is linked to specific circulation patterns (or their absence) over Iberia. The North Atlantic Oscillation (NAO) is recognised as one of the major teleconnections in the Northern Hemisphere (van Loon and Rogers, 1978; Rogers, 1990; Wallace et al., 1995) and is also known to make a major contribution to the winter circulation over Western Europe. It is, therefore, reasonable to expect that it should play some significant role in the behaviour of ECDs in the Madrid region. When the NAO is its positive phase, the Iberian Peninsula is under the direct influence of the Azores High, which is then more intense than during the negative phase, at which time the principal storm track lies closer to Iberia. Thus, during NAO positive winters the incidence of STA and BP patterns (linked to deeper anticyclones) should be greater than during the NAO negative winters. However, this relationship may not be easy to detect since the NAO is defined at monthly or seasonal scales, while ECDs are extreme, sub-monthly phenomena, linked to the $5 \%$ extremity of the distribution. Their incidence might not therefore be wholly sensitive to changes in the NAO index averaged over the same winter season.

To evaluate any possible relationship, the winter NAO index, defined as the SLP anomalies between Azores and Iceland (Jones et al., 1997) and computed by the Climate Research Unit of the East Anglia University, has been used jointly with the total ECD counts and the counts associated 


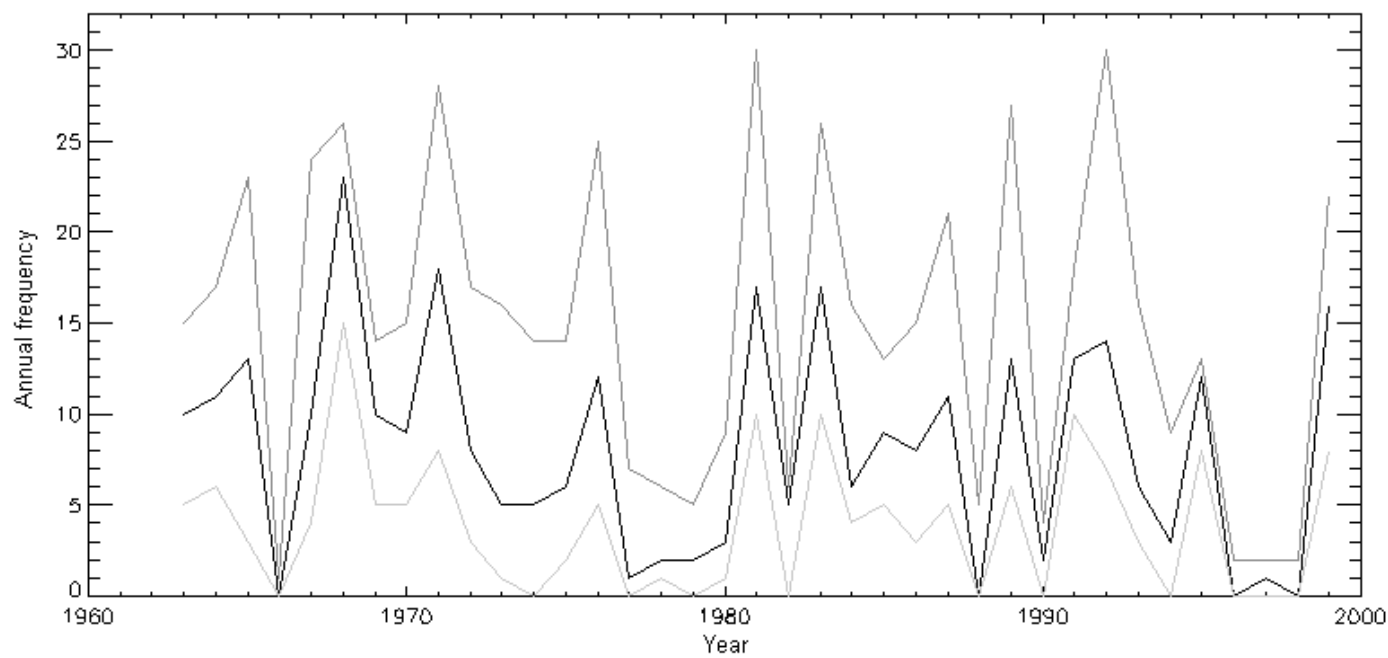

Fig. 5. Annual ECD frequency series associated with different temperature thresholds: $-4.6^{\circ} \mathrm{C}$ (black), $-3.6^{\circ} \mathrm{C}$ (dark grey) and $-5.6^{\circ} \mathrm{C}$ (light grey).

Table 3. Correlations between total annual frequency of the different pattern and the NAO winter index

\begin{tabular}{ccccccc}
\hline & TOTAL & PM & CPN & CPE & STA & BP \\
\hline NAO & 0.13 & 0.009 & -0.007 & -0.127 & 0.257 & 0.036 \\
\hline
\end{tabular}

with each of the five patterns. Table 3 shows the correlation coefficients between the winter NAO index and the number of ECDs per winter corresponding to every pattern and to the total ECDs.

It can be seen that none of the values is significant, suggesting that there is no significant linear relationship between the NAO and the number ECDs series. To explore the existence of any nonlinear relationship, a sub-sample of extreme NAO winters was considered, since it is likely that an extreme seasonal value should exhibit a higher probability of generating more intense anomalies at a daily scale. To check this, the average winter number of ECDs was computed for the five most positive (1989, 1995, 1990, 1983 and 1984) and for the five most negative (1996, 1969, 1979, 1977 and 1965) winters. Over the five most negative NAO winters the average number of ECDs was 5.2. For the five most positive, this value almost doubled to 9.4 .

Table 4 shows the results obtained when partitioning the number of ECD per winter among the different patterns. It is evident that the first three patterns, associated with active air circulations, show only small differences, while the patterns associated with stagnant situations reveal a significant increase (decrease) in the number of occurrences during NAO positive (negative) winters.

It appears that the NAO extremes influence the number of ECDs per winter through the agency of the STA pattern. To test the significance of the differences between the patterns,
Table 4. Mean frequencies of ECDs over the 5 years with most negative and positive NAO indices and for the whole period (TOTAL)

\begin{tabular}{cccccc}
\hline & PM & CPN & CPE & STA & BP \\
\hline NAO - & 1.2 & 1.8 & 1.0 & 1.0 & 0.0 \\
$\mathrm{NAO}+$ & 1.0 & 1.6 & 0.6 & 4.0 & 1.2 \\
TOTAL & 1.1 & 1.25 & 0.9 & 2.6 & 1.3 \\
\hline
\end{tabular}

the confidence intervals of the sample estimates of the Poisson parameter have been computed as:

$I_{0}=\widehat{\lambda} \pm z \frac{\alpha}{2} \sqrt{\frac{\widehat{\lambda}}{n}}$

where $\widehat{\lambda}$ is the average number of ECDs per winter, $\alpha$ the confidence level $n$ the number of years and $z$ the normal distribution. The results show that the difference for the total number of ECDs becomes significant at probability $<0.08$, while for STA and BP patterns significance is at $p<0.03$. An alternative check for significance is to compute the distribution of the Poisson parameter over the two different fiveyear extreme NAO groups. Figure 7 shows the two different distributions using the total numbers of ECDs per winter, the small overlap corresponds to a $10 \%$ probability. The figure suggests that during NAO extremes the process generating ECDs changes its characteristics, being more probable and with a flatter distribution for extremely NAO positive years.

Having examined the influence exercised by the NAO on ECD frequencies, attention can now be turned to the former's influence on the SLP anomaly fields. The average SLP anomaly has been computed for each of the five patterns over each of the two extreme groups. The areas with a statistically significant anomaly have been identified through 

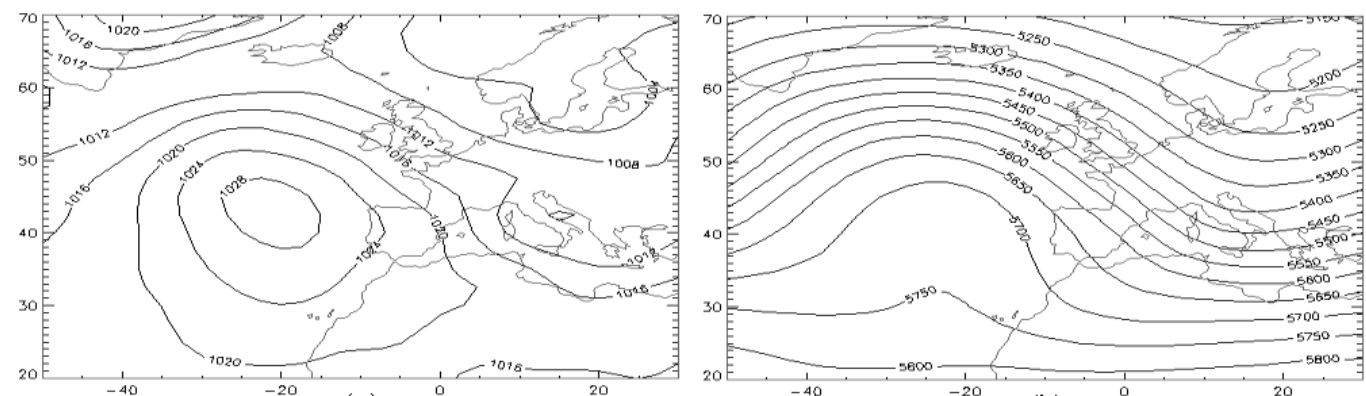

(a)

(b)
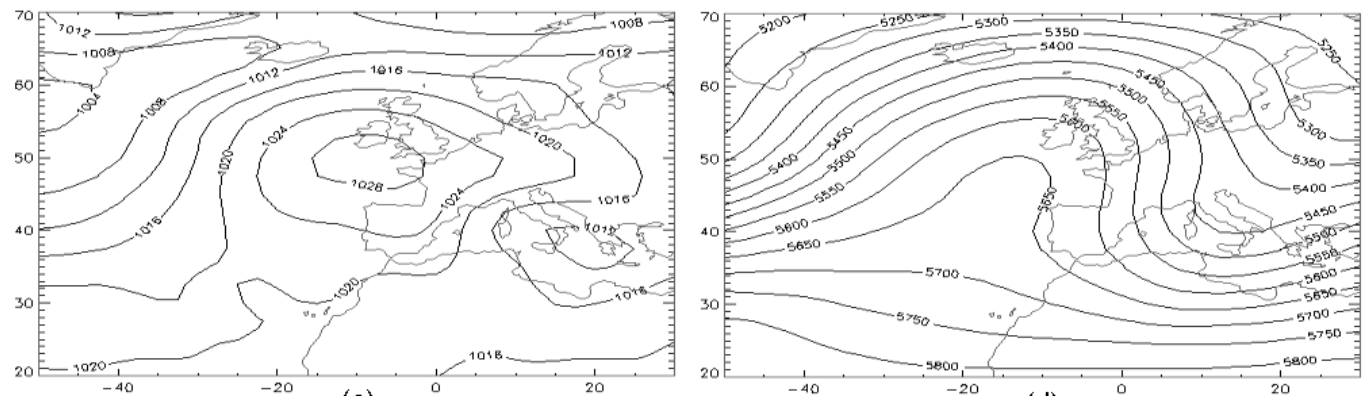

(c)
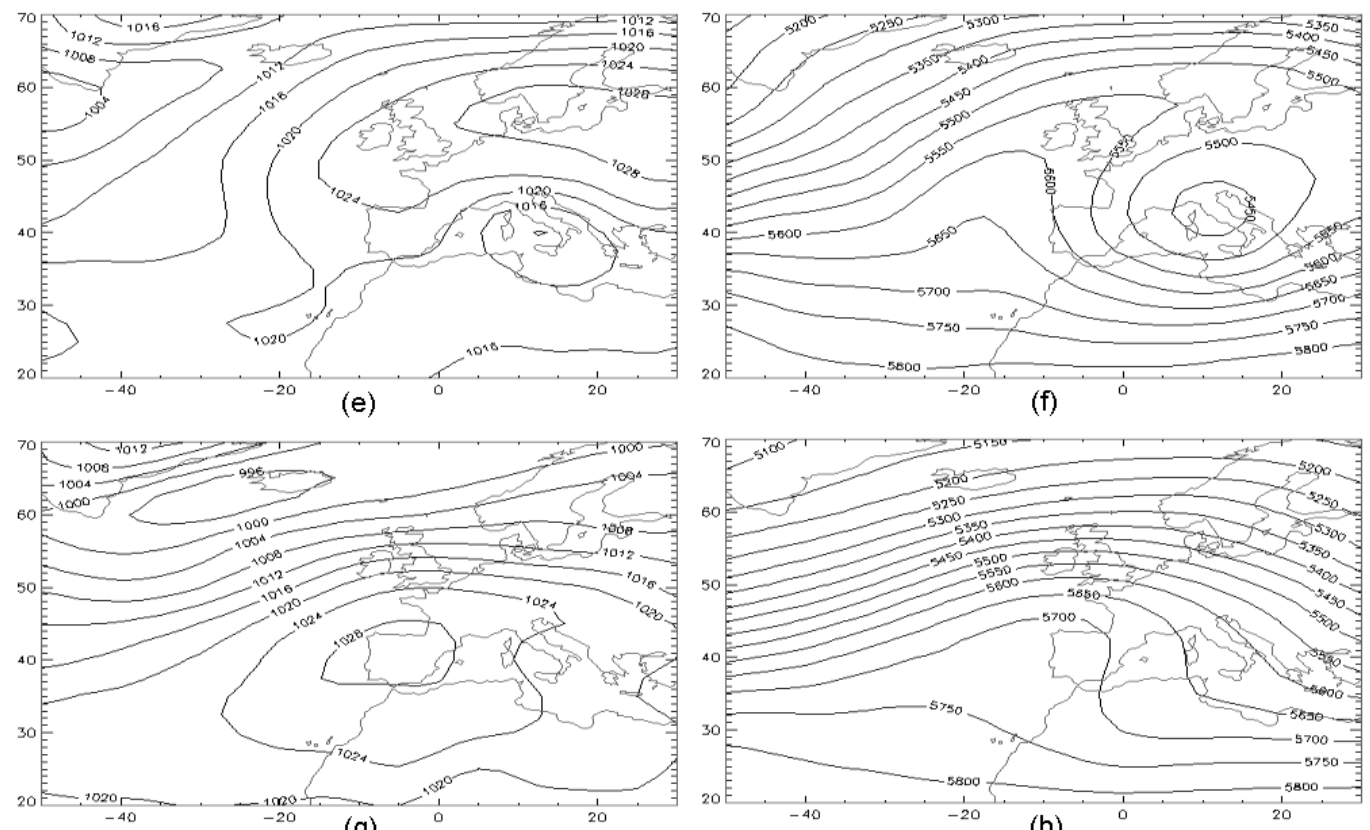

(g)
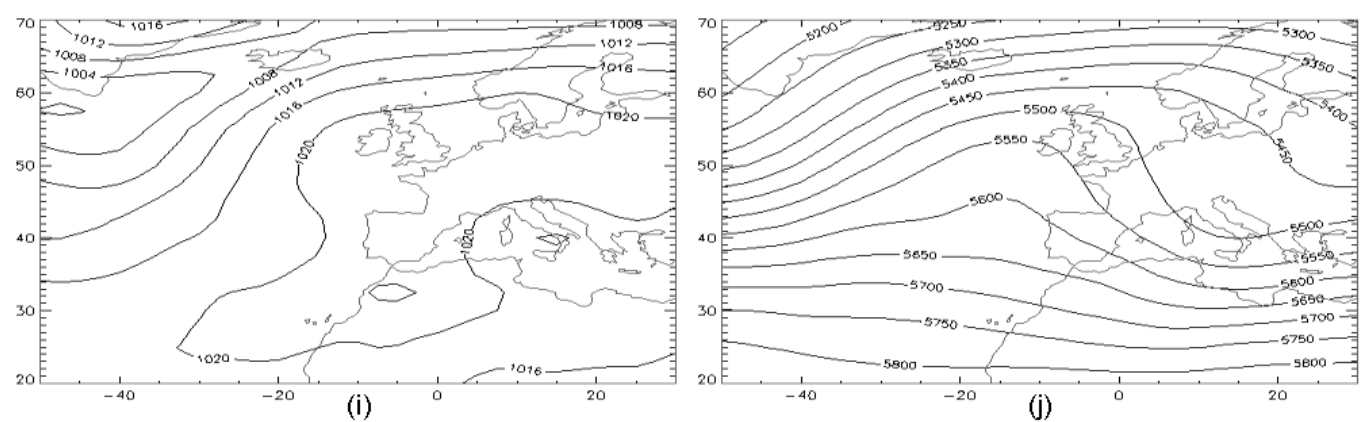

Fig. 6. SLP and $500 \mathrm{hPa}$. average fields associated to the five patterns: PM (a, b), CPN (c, d), CPE (e, f), STA (g, h) and BP (i, j). 


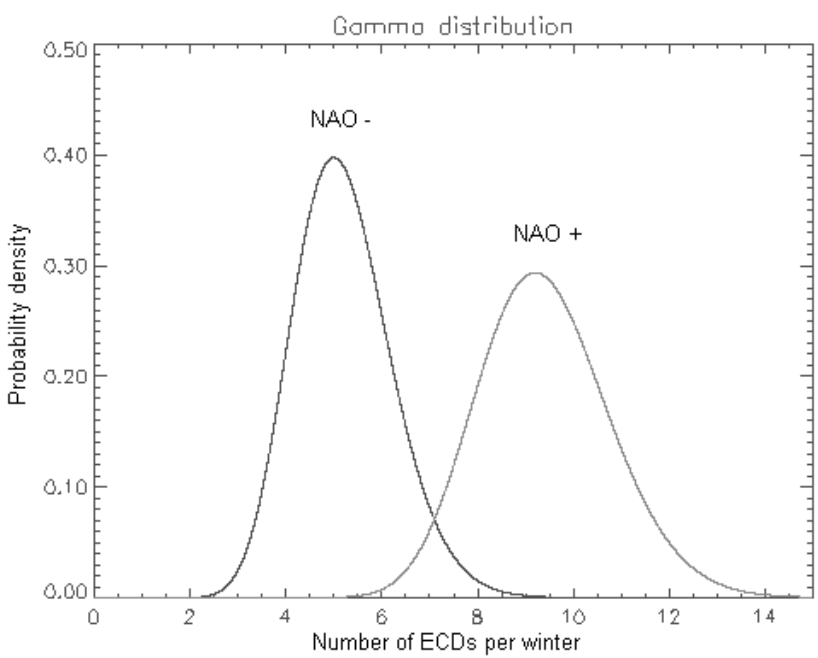

Fig. 7. As in Fig. 3, but for the 5 NAO most positive years (1983, $1984,1989,1990$ and 1995) and for the 5 NAO most negative years (1965, 1969, 1977, 1979 and 1996).

a Monte Carlo test with 1000 random simulations. Only two patterns exhibit significant anomalies, the CPE and the STA. These are depicted in Figs. 9a and b, respectively, in which the left (right) show SLP anomalies associated with NAO $(+)$ years. The shaded areas indicate a significant $(p<0.05)$ difference between the anomalies. It can be seen that during NAO positive years, the anticyclone centred over Poland is the dominant feature, while during NAO negative years, the low pressure system over Italy is reinforced and the anticyclone is displaced westward. In Fig. 9b the intensification of the pressure anomaly over Iberia during NAO positive years assumes the dominant role.

The previous paragraphs show that the association between the NAO and number of ECDs per winter is not linear and that much depends on the STA patterns. The use of generalised linear models allows a clearer impression of these associations. This type of model has been successfully applied previously to describe meteorological extreme events such as hurricanes (Elsner and Bossak, 2001). Adopting a similar approach, the dependence of number of ECD on NAO phase can be described by the following expressions:

$\lambda=\exp \left(\beta_{0}+X \beta_{1}\right)$

where $\lambda$ is the Poisson parameter of the winter number of ECDs and $X$ the value of the winter NAO index. Coefficient $\beta_{0}$ and $\beta_{1}$ measure the NAO influence on the average number of ECDs per winter. The model output is a parameter characterising the process, i.e. a probability density function centred on the estimated value. No significant results are obtained when the model is applied using the total number of ECDs as the dependent variable. This can be attributed to the fact that most of the NAO-related variability is concentrated in the STA pattern. When the number of ECDs of this pattern is the dependent variable, the results are significant $(p<0.05)$, with the following parameters values: $\beta_{0}=0.84$ std error $=0.11$

$\beta_{1}=0.24$ std error $=0.08$.

However, this model explains only $6.5 \%$ of the variance, which does not seem satisfactory, and a better performance can be obtained if the data are partitioned between NAO positive and NAO negative years. In this case, the parameters values are, for negative years:

$\beta_{0}=1.72$ std error $=0.26$

$\beta_{1}=1.01$ std error $=0.39$,

with $19.3 \%$ of explained variance, while for positive years, the model explains $13.9 \%$ with the following parameter values:

$$
\beta_{0}=0.45 \text { std error }=0.22
$$$$
\beta_{1}=0.44 \text { std error }=0.14
$$

Figure $9 \mathrm{a}$ represents the Poisson parameter versus the NAO index for the three modes. It is clear that, since the NAO extremes behave as two different ECD populations, no single model, even if it is non-linear, can produce a satisfactory estimate. A more realistic way to model this dependence would be to combine the models as shown in Fig. 9b. It can be seen that Poisson parameter should vary in three phases: for the lowest NAO values, as identified previously; for intermediate NAO values $(-1$ to 1$)$ where it maintains constant around its average value 2.8 , and, finally for the higher NAO values $(>1)$, where the parameters for the extreme positive years are applied. This model improves the explained variance and, provides a more realistic view of the nature of the relationship between ECD and NAO.

\section{Final remarks}

The series used in this study has been carefully chosen to preclude the effects of the urban heat island. In this context, it is important to note that no significant trends have been detected either in the minimum temperature series or in the number of ECDs per winter during what has been a period of general warming. The latter usually manifests as increasing minimum temperatures (Karl et al., 1993). This is not unexpected as previous studies (Easterling et al., 1997) show that, at local scale, the trends in the minimum temperature are highly variable. At the same time, the recent NAO record has exhibited an unprecedently long period of positive values (Hurrel, 1995). In the case of Madrid, this has resulted in a higher number of stagnant episodes and, consequently, a trend towards lower minimum temperature and higher number of ECDs per winter. This mechanism could explain the local discrepancy with regard to the global trend which has been characterised by generalised warming. Thus both trends, having opposite signs, should be mutually compensating, thereby producing a series without a significant trend as is the case.

The NAO impact on surface temperatures in Western Europe is well known (Hurrel, 1996). The intensification of western circulation during NAO positive years leads to a temperature increase over most of Europe, except Iberia, Southern Italy and Greece, where no significant correlations are 

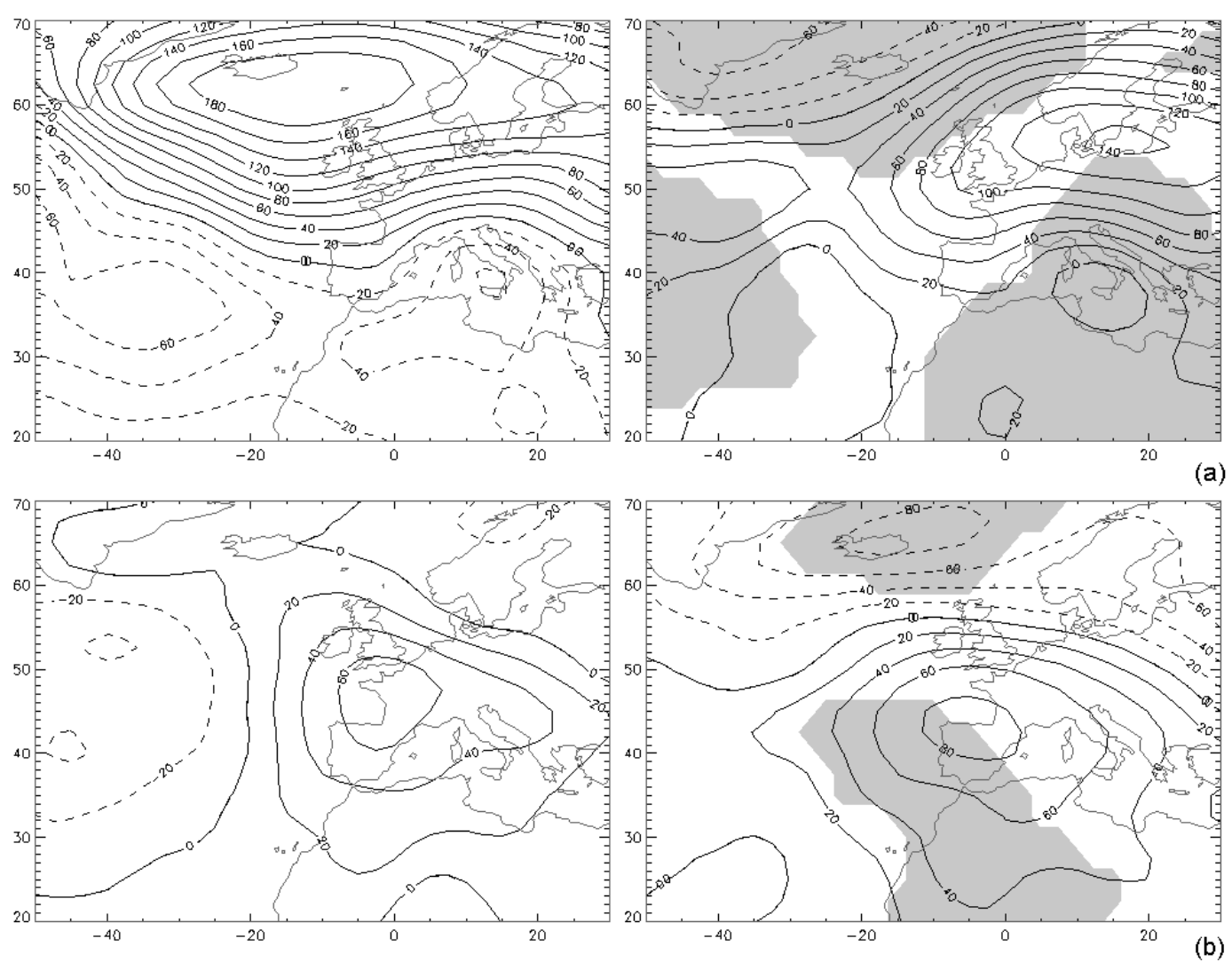

Fig. 8. Anomalies of geopotential at $1000 \mathrm{hPa}$. in NAO positive years (right) and negative (left) for the patterns: (a) CPE and (b) STA. Shaded areas represent significant $(p<0.05)$ anomaly differences.
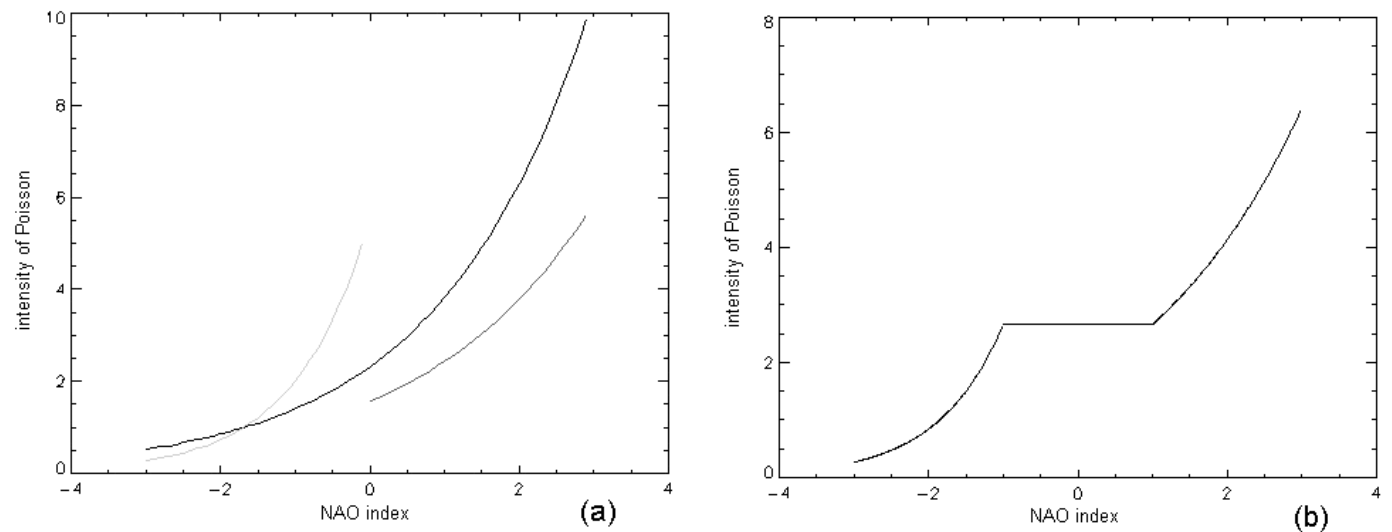

Fig. 9. (a) Log-linear models adjustments for: (black) total series, (dark grey) positive NAO years and (light grey) negative NAO years. (b) Proposed model for the association between the annual ECD frequency and the NAO index values.

found. However, this paper shows that an identifiable NAO signal exists in the area, with a clear mechanism. During NAO positive years, the circulation of low pressure systems over Iberia is inhibited, leading to stagnant situations which are the conditions most frequently responsible for extremely low temperatures. On the contrary, during NAO negative years, the storm track reaches lower latitudes and such stagnant situations are much less frequent over the region. This
ECD-NAO relationship is clearly non-linear, and a more realistic statistical representation can only be made using a combination of different log-linear generalised models.

Acknowledgements. The authors thank D. A. Wheeler for his extremely helpful review which improved substantially the manuscript and two anonymous reviewers for their comments. The INM for providing the data.

Topical Editor J.-P. Duvel thanks two referees for their help in evaluating this paper. 


\section{References}

Alberdi, J. C., Diaz, J., Montero, J. C., and Miron I. J.: Daily mortality in Madrid Community (Spain) 1986-1991: Relationship with atmospheric variables, European Journal of Epidemiology, 14, 571-578, 1998.

Diaz, J., Lopez, C., Jordan, A., Alberdi, J. C., García, R., Hernández, E., and Otero, A.: Heat waves in Madrid, 19861997: Effects on the health of the elderly, International Archieves Occupational and Environmental Health, On line, Nov., 2001.

Easterling, D. R., Horton, B., Jones, P. D., Peterson, T. C., Karl, T. R., Parker, D. E., Salinger, M. J., Razuvayev, V., Plummer, N., Jamason, P., and Folland, C. K.: Maximum and minimum temperature trends for the globe, Science, 277, 364-367, 1997.

Easterling, D. R., Evans, J. L., Groisman, P. Y., Karl, T. R., Kunkel, K. E., and Ambenje, P.: Observed Variability and Trends in Extreme Climate Events: A Brief Review, Bulletin of the American Meteorological Society, 81, 417-425, 2000.

Elsner, J. B. and Bossak, B. H.: Changes in hurricane landfall probabilities in response to variations in climate. Hurricanes and Typhoons: Past, Present, and Future, Columbia University Press, 2001.

Elsner, J. B. and Bossak, B. H.: Bayesian analysis of U. S. hurricane climate, J. of Climate, 14, 4341-4350, 2001.

Epstein, E. S.: Statistical inference and prediction in climatology: a bayesian approach, Meteorological Monographs, 20, Am. Meteo. Soc., 1985.

Frost, D. J. and Auliciems, A.: Myocardial infarct death, the population at risk and temperature habituation, International journal of biometeorology, 37, 46-51, 1993.

Hurrel, J. W.: Decadal trends in the North Atlantic Oscillation regional temperatures and precipitation, Science, 269, 676-679, 1995.

Hurrel, J. W.: Influence of variations in extratropical wintertime teleconnections on Northern Hemisphere temperatures, Geophys. Res. Lett., 23, 665-668, 1996.

Jendritzky, G.: Comnplex environmental effects: Climate, Practical environmental health, 4th supplement, Heidelberg, Springer, 130, 1996.

Jones, P. D., Johnson, T., Wheeler, D., et al.: Extension to the North Atlantic Oscillation using early instrumental pressure observations from Gibraltar and South-West Iceland, Int. J. of Climatology, 17, 1433-1450, 1997.

Kalnay, E., Kanamitsu, M., Kistler, R., et al.: The NCEP/NCAR 40-year reanalysis project, Bull. Am. Meteo. Soc., 77, 437-471, 1996.

Kalkstein, L. S. and Davis, R. E.: Weather and human mortality: an evaluation of demographic and inter-regional responses in the
U.S., Annals of the Association of American Geographers, 79, 44-64, 1989.

Karl, T. R., Kukla, G., Razuvayev, V. N., et al.: Global warming: evidence for asymmetric diurnal temperature change, Geophys. Res. Lett., 18, 2253-2256, 1991.

Karl, T. R., Jones, P. D., Knight, R. W., et al.: Asymmetric trends of daily maximum and minimum temperature, Bull. Am. Meteor. Soc., 74, 1007-1023, 1993.

Katsouyanni, K., Pantazopoulou, A., Touloumi, G., et al.: Evidence for interaction between air pollution and high temperature in the causation of excess mortality, Archives of Environmental Health, 48, 235-242, 1993.

Kattenberg, A., Giorgi, F., Grassl, H., et al.: Climate change 1995: The Science of Climate Change, Intergovernmental Panel on Climate Change (IPCC), Cambridge Univ. Press, 285-357, 1996.

Keatinge, W. R., Coleshaw, S. R. K., Holmes, J., et al.: Changes in seasonal mortalities with improvement in gome heating in England and Wales from 1963-1984, Int. J. of Biometeorology, 33, 71-76, 1989.

Kunst, A. E., Looman, C. W. N., Mackenbach, J. P., et al.: Outdoor air temperature and mortality en the Netherlands: a time-series analysis, American J. of Epidemiology, 137, 331-341, 1993.

Nicholls, N., Gruza, G. V., Jouzel, J., et al.: Climate change 1995: The Science of Climate Change, Intergovernmental Panel on Climate Change (IPCC), Cambridge Univ. Press, 133-192, 1996.

NOAA, Impact Assessment: U. S. Social and Economic Effects of the Record 1976-1977 Winter Freeze and Drought, U. S. Department of Commerce, National Oceanic and Atmospheric Administration, Environmental Data and Information Service, Center for Environmental Assessment Services, 1982.

NOAA, Storm Data: U. S. Department of Commerce, National Oceanic and Atmospheric Administration, National Climate Data Center, 1983.

Rogers, J. C.: Patterns of low-frequency monthly sea level pressure variability (1899-1986) and associated wave cyclone frequencies, J. of Climate, 3, 1364-1379, 1990.

Van Loon, H. and Rogers, J. C.: The seesaw in winter temperatures between Greenland and Northern Europe, Part I: General description, Mon. Wea. Rev., 106, 296-310, 1978.

Wallace, J. M., Zhang, Y., and Renwick, J. A.: Dynamic contribution to hemispheric mean temperature trends, Science, 270, 780-783, 1995.

Yague, C., Zurita, E., Martinez, A., et al.: Statistical analysis of the Madrid urban heat island, Atmospheric Environment, 25B, 327-332, 1991.

Zwiers, F. W. and Kharin, V. V.: Changes in the extremes of the climate simulated by CCC GCM2 under CO2 doubling, J. of Climate, 11, 2200-2222, 1998. 